Editorial

\title{
Biomarkers and personalized medicine for disease diagnosis and treatment
}

\section{Editorial}

Biomarker is an important tool for disease diagnosis and tracking. Blood pressure, lipid, and sugar are simple example of biomarkers. According to the definition by (Food and Drug Administration, FDA), biomarkers can be any analytic method to detect or to predict general physiological response, disease progression, or patient's therapeutic response and safety to drug treatment. The parameter of metabolite, gene or protein expression regards as an indicator in clinical manifestation. ${ }^{1}$

Base on the clinical reports, experience, and statistics, majority patient are not responsive to pharmacological regimen. For example, $4 \%$ to $70 \%$ asthma patient is non-responsive to bronchodilators; $50 \%$ to $75 \%$ patient is only little response to oral hypoglycemic agents. Importantly, cancer patient has no effect after chemotherapy. In addition, systemic anaphylaxis is highly associated with patient genomic profiling. Hence, patient biomarker is critical indicator for providing proper drug treatment and preventing adverse effect. This information triggered the developing trend of personalized medicine.

During the past decade, tumor marker is becoming the most important topic in the field cancer research. It is a crucial reference for physician to treat patient with target therapy. With the feature of, simplicity, high sensitivity and accuracy, current medical technology allowed us to characterize specific molecule from patient's tissue,

Table I Biomarkers for cancer drug

\author{
Volume I Issue I - 2014 \\ Jun-Jie Chen \\ Department of medical research, E-da hospital in Kaohsiung, \\ Taiwan
}

\begin{abstract}
Correspondence: Jun-Jie Chen, Department of medical research, E-da hospital in Kaohsiung, Rm I0503-2, Incubation and Research Bldg, No. 6,Yi-Da Road, Yan-Chao District, Kaohsiung City 824,Taiwan, Tel +88676I5II0059I3,
\end{abstract} Email 107368@edah.org.tw

Received: April 14, 2014 | Published: April 24, 2014

body fluid, and peripheral blood ${ }^{2}$ (Table 1) With the development of next generation sequencing, this technology facilitates clinical physician to diagnose the genetic profile and somatic mutation of patient. Bioinformatic data provide a great evidence for disease characterization and pharmacotherapy. In the case of non small cell lung cancer (NSCLC), Erlotinib is a specific inhibitor to block EGFR which is only used for treatment of patient with EGFR mutation or over expression. Clinical research revealed this drug particularly is effective in the tumor harboring exon 19 or 21 mutation. In the other case, approximately 7\% NSCLC patient has EML4-ALK rearrangement, FDA approved ALK inhibitor-Crizotinib for treating this kind indication.

\begin{tabular}{|c|c|c|}
\hline Agents & Biomarker & Indicative group \\
\hline Afatinib & EGFR & EGFR exon 19 deletion or exon 21 substitution (L858R) mutation positive \\
\hline Arsenic Trioxide & PLIURARA & PUIL/RARa $(\mathrm{t}(15: 17))$ gene expression positive \\
\hline Bosutinib & $B C R / A B L I$ & Philadelphia chromosome $(\mathrm{t}(9: 22))$ positive \\
\hline Brentuxirnab & TNFRSF8 & CD30 positive \\
\hline Cetuximab & EGFR & EGFR protein expression positive \\
\hline Cetuximab & KRAS & KRAS codon 12 and 13 mutation negative \\
\hline Crizotinib & ALK & ALK gene rearrangement positive \\
\hline Dabrafenib & BRAF & BRAFV600E mutation positive \\
\hline Dasatinib & $B C R / A B L I$ & Philadelphia chromosome $(\mathrm{t}(9: 22))$ positive; $\mathrm{T3}$ I5I mutation-positive \\
\hline Denileukin & IL2RA & CD25 antigen positive \\
\hline Erlotinib & EGFR & EGFR exon 19 deletion or exon 21 substitution (L858R) positive \\
\hline Exemestane & ESRI & Estrogen receptor positive \\
\hline Fulvestrant & ESRI & Estrogen receptor positive \\
\hline Ibriturnomab & LIS4AI & CD20 positive \\
\hline Lmatinib & $\mathrm{BCR} / \mathrm{ABLI}$ & Philadelphia chromosome $(\mathrm{t}(9: 22))$ positive \\
\hline Lapatinib & ERBB2 & HER2 protein over expression positive \\
\hline Letrozole & ESRI.PGR & Hormone receptor positive \\
\hline
\end{tabular}


Table Continued....

\begin{tabular}{|c|c|c|}
\hline Agents & Biomarker & Indicative group \\
\hline Rlilotinib & $\mathrm{BCR} / \mathrm{ABLI}$ & Philadelphia chromosome $(\mathfrak{t}(9: 22))$ positive \\
\hline Omacetaxine & $\mathrm{BCR} / \mathrm{ABLI}$ & BCR-ABLT3I5I \\
\hline Panitumumab & KRAS & KRAS cotton 12 and 13 mutation negative \\
\hline Pertuzumab & ERBB2 & HER2 protein over expression positive \\
\hline Ponatinib & $\mathrm{BCR} / \mathrm{ABLI}$ & Philadelphia chromosome $(\mathrm{t}(9 ; 22))$ positive. BCR-ABL T3।5I mutation \\
\hline Rituximab & M S4M & CD20 positive \\
\hline Tamoxifen & ESRI.PGR & Hormone receptor positive \\
\hline Trametinib & BRAF & BRAFV600E/K mutation positive \\
\hline Trastuzumab & ERBB2 & HER2 protein over expression positive \\
\hline Tretinoin & PMURARA & PMIJRAR0 $(\mathrm{t}(15 ; 17))$ gene expression positive \\
\hline Vemurafenit & BRAF & BRAFV600E mutation positive \\
\hline
\end{tabular}

On the other hand, biomarkers can be applicable for understanding the mechanism of drug resistance. Cetuximab is a therapeutic monoclonal antibody which is also targeting EGFR. Its indication is for colon cancer. However, some patient with KRAS gene mutation is not eligible for the utilization of this agent. ${ }^{3}$

All these example indicated and emphasized the importance and application of biomarkers in clinical. New diagnostic technology have considerable potential to improve care, target treatment, and reduce the cost of unnecessary prescriptions and the downstream effects of drug resistance and increase the accuracy of pharmacotherapy. The postgenomic era has been launched by significant enthusiasm for therapeutic individualization through the use of pharmacogenomic and other biomarkers. This enthusiasm has been dampened by limited examples of widespread clinical adoption. Future studies of putative biomarkers are likely to give additional information to clearly define which patients receive therapeutic benefit from target therapy.

\section{Acknowledgements}

None.

\section{Conflict of interest}

The author declares no conflict of interest.

\section{References}

1. Zineh I, Huang SM. Biomarkers in drug development and regulation: a paradigm for clinical implementation of personalized medicine. Biomark Med. 2011;5(6):705-713.

2. Godman B, Finlayson AE, Cheema PK, et al. Personalizing health care: feasibility and future implications. BMC Med. 2013;11:179.

3. Stenvang J, Kumler I, Nygard SB, et al. Biomarker-Guided Repurposing of Chemotherapeutic Drugs for Cancer Therapy: A Novel Strategy in Drug Development. Front Oncol. 2013;3:313. 